\section{Pengaruh Variasi Campuran Agregat Kelas A terhadap Koefisien Permeabilitas Horizontal}

\author{
Fariz Baihaqii ${ }^{1}$, Rustam Efffendi ${ }^{2}$ \\ 1 Pimpinan perusahaan bidang kontraktor umum CV. \\ Yorisindo Putera Perkasa \\ 2Program Studi Teknik Sipil, Universitas Lambung \\ Mangkurat
}

baihaqifariz@gmail.com

\begin{abstract}
Gradasi aktual LPA setelah dipadatkan akan bergeser keluar melampaui batas atas spesifikasi sebagai pengaruh terhadap perbedaan nilai abrasi. Sehingga perlu didesain campuran gradasi di bawah batas bawah spesifikasi agar setelah pemadatan diharapkan gradasi akan bergeser masuk ke dalam spesifikasi. Material yang digunakan adalah LPA dari lokasi Gunung Kayangan dan Katunun, Kalimantan Selatan yang telah dipadatkan sesuai OMC. Dengan berbagai macam variasi gradasi campuran yang mengacu pada Spesifikasi Bina Marga 2010 revisi ke-3. Metode yang digunakan adalah uji permeabilitas skala laboratorium dengan arah pengaliran horisontal menggunakan alat fabrikasi yang terkalibrasi melalui sampel pasir. Uji analisa saringan dilakukan setelah proses pemadatan dan uji permeabilitas dilakukan agar dapat diketahui ukuran aktual butiran setelah dipadatkan. Persamaan $\mathrm{y}=0,00018 \mathrm{x} 2-0,02674 \mathrm{x}+\mathbf{0 , 9 5 2 2 9}$ dapat digunakan untuk desain di bawah dari batas bawah spesifikasi. Gradasi butiran yang terpotong pada saringan No. 40 cenderung mempunyai nilai koefisien permeabilitas yang besar yakni $5,52 \times 10^{-2} \mathrm{~cm} /$ det. Pada penerapan di lapangan, dengan memberikan kemiringan permukaan LPA = 3\% pada badan jalan kelas I dengan lebar $7 \mathbf{m}$ dan panjang lintasan pengaliran 3,5 m, maka air yang menggenangi jalan akan hilang dalam waktu 2,45 hari. Menurut AASHTO (1993) drainase termasuk ke dalam kategori drainase dengan kualitas baik menuju sedang.
\end{abstract}

Kata kunci: pondasi agregat Kelas A (LPA), permeabilitas horisontal, variasi gradasi, abrasi.

Diajukan: 9 Juli 2019

Direvisi: 16 Juli 2019

Diterima: 22 Juli 2019

Dipublikasikan online: 22 Juli 2019

\section{Pendahuluan}

Jaringan jalan raya merupakan prasarana transportasi darat yang memegang peranan penting dalam sektor perhubungan terutama untuk kesinambungan distribusi barang dan jasa (Hendarsin, 2000). Salah satu transportasi yang berkembang di Indonesia adalah transportasi darat, dimana kegiatan masyarakat tidak terlepas dari sarana dan prasarana transportasi tersebut. Akibat dari kegiatan masyarakat ini menyebabkan terjadi pergerakan dari satu tempat ke tempat lain yang mempengaruhi volume lalu lintas. Volume lalu lintas berbanding lurus dengan kegiatan masyarakat. Semakin meningkat kegiatan masyarakat maka volume lalu lintas akan semakin tinggi (Aminsyah, 2013). Hal tersebut memicu pekerjaan konstruksi perkerasan jalan raya dihampir setiap daerah. Pekerjaan konstruksi perkerasan jalan yang umum digunakan di Indonesia ada dua yaitu perkerasan lentur (flexible pavement) dan perkerasan kaku (rigid pavement). Menurut Razali (2012), salah satu jenis perkerasan yang sering digunakan di Indonesia adalah lapis beton aspal (Laston) atau $A C$
(Asphalt Concrete). Pada perkerasan diperlukan lapis fondasi berupa campuran agregat yang terletak di antara lapisan permukaan (Wearing Course) dan tanah dasar (Subgrade).

Lapis fondasi terdiri dari Lapis Fondasi Agregat Kelas A (LPA) dan atau Lapis Fondasi Agregat kelas B (LPB). Menurut Sukirman (2010) LPA berfungsi sebagai bagian struktur perkerasan yang menahan gaya vertikal dari beban kendaraan dan disebarkan ke lapis di bawahnya dalam hal ini LPB maupun tanah dasar. Disamping itu LPA juga berfungsi sebagai bantalan atau perletakan lapis permukaan serta sebagai lapisan peresapan atau sistem drainase bawah permukaan. Lapis ini harus cukup stabil dan mempunyai $C B R$ sama atau lebih besar dari $20 \%$, serta indeks plastisitas $\left(I_{\mathrm{P}}\right)$ sama atau lebih kecil dari $10 \%$.

Menurut Bina Marga (2010), LPA terdiri dari gabungan antara fraksi agregat kasar dan fraksi agregat halus. Fraksi agregat kasar yang tertahan pada ayakan 4,75 $\mathrm{mm}$ harus terdiri dari partikel atau pecahan batu yang keras dan awet yang memenuhi persyaratan. Sedangkan fraksi agregat halus adalah partikel pasir alami atau batu pecah halus dan partikel halus lainnya

Cara mensitasi artikel ini:

Baihaqi, F., dan Effendi, R (2019) Pengaruh Variasi Campuran Agregat Kelas A Terhadap Koefisien Permeabilitas Horizontal. Buletin Profesi Insinyur 2(1) 029-035 
yang lolos ayakan $4,75 \mathrm{~mm}$ dan memenuhi persyaratan sesuai dengan peraturan terbaru yaitu Spesifikasi Bina Marga tahun 2010 revisi ke-3. Distribusi gabungan fraksi agregat kasar dan fraksi agregat halus memiliki batasan minimum dan maksimum seperti pada Gambar 1.

Pada dasarnya setiap perkerasan jalan akan mengalami proses kerusakan progresif sejak suatu jalan dibuka pertama kali untuk melayani lalu lintas. Tipe kerusakan umum yang dialami campuran laston adalah retak dan atau pelepasan butir (Razali dkk, 2012). Apabila terjadi retak pada lapisan aspal kemudian air hujan akan merembes masuk dan tidak mampu dialirkan ke samping oleh lapis fondasi agregat maka air akan terperangkap di dalam lapisan tersebut. Kemudian apabila jalan dilewati beban kendaraan maka akan terjadi pumping yang akan mengakibatkan pertambahan tekanan air pori pada lapis fondasi agregat secara fluktuatif. Pertambahan tekanan air pori secara otomatis akan mengurangi tegangan efektif agregat, sehingga daya dukung akan berkurang dan akan berdampak pada kerusakan lapis fondasi agregat bahkan dapat menjalar hingga ke tanah dasar. Hal tersebut tentu akan berdampak pada lapis permukaan di atasnya sehingga lambat laun jalan akan berlubang dan mengalami kerusakan. Menurut Sukirman (2003), Agregat dapat mengalami degradasi, yaitu perubahan gradasi akibat pecahnya butir-butir agregat. Kehancuran agregat dapat disebabkan oleh proses mekanis, seperti gaya-gaya yang terjadi selama proses pelaksanaan perkerasan jalan (penimbunan, penghamparan, pemadatan), pelayanan terhadap beban lalu lintas, dan proses kimiawi.

Perilaku merembesnya air hujan serta pengalirannya melalui lapis fondasi agregat menuju drainase samping tentunya sangat erat kaitannya dengan parameter permeabilitas agregat. Menurut Halauddin dan Suhendra (2011), koefisien permeabilitas tanah sangat tergantung pada ukuran rata-rata pori yang dipengaruhi oleh distribusi ukuran partikel, viskositas, bentuk partikel dan struktur tanah. Semakin kecil ukuran partikel tanah, semakin kecil pula ukuran pori dan semakin rendah kemampuan tanah tersebut untuk melewatkan fluida. Pengaruh distribusi ukuran partikel tentunya berkaitan erat dengan bentuk kurva gradasi. Dari latar belakang di atas, muncul permasalahan diantaranya adalah seberapa efektifkah lapis fondasi agregat dalam memenuhi fungsinya sebagai sistem drainase bawah permukaan apabila ditinjau dari segi distribusi agregat yang beragam.

\section{Metode}

Lokasi pengambilan LPA adalah di Gunung Kayangan dan Katunun Kab. Tanah Laut, Provinsi Kalimantan Selatan. Dikarenakan tidak terdapat alat khusus untuk melakukan uji permeabilitas Horizontal LPA, maka dilakukan fabrikasi alat yang terlebih dahulu melalui tahap desain alat. Desain Alat dapat dilihat pada Gambar 2. Setelah alat di fabrikasi maka tahap selanjutnya adalah pengujian awal untuk mengkalibrasi alat menggunakan pasir. Kemudian menentukan rancangan komposisi campuran agregat dengan berpedoman kepada syarat-syarat gradasi campuran menurut spesifikasi Bina Marga 2010 revisi ke-3. Tabel Desain campuran LPA dapat dilihat pada Tabel 1. Sedangkan kurva rancangan dapat dilihat pada Gambar 3.

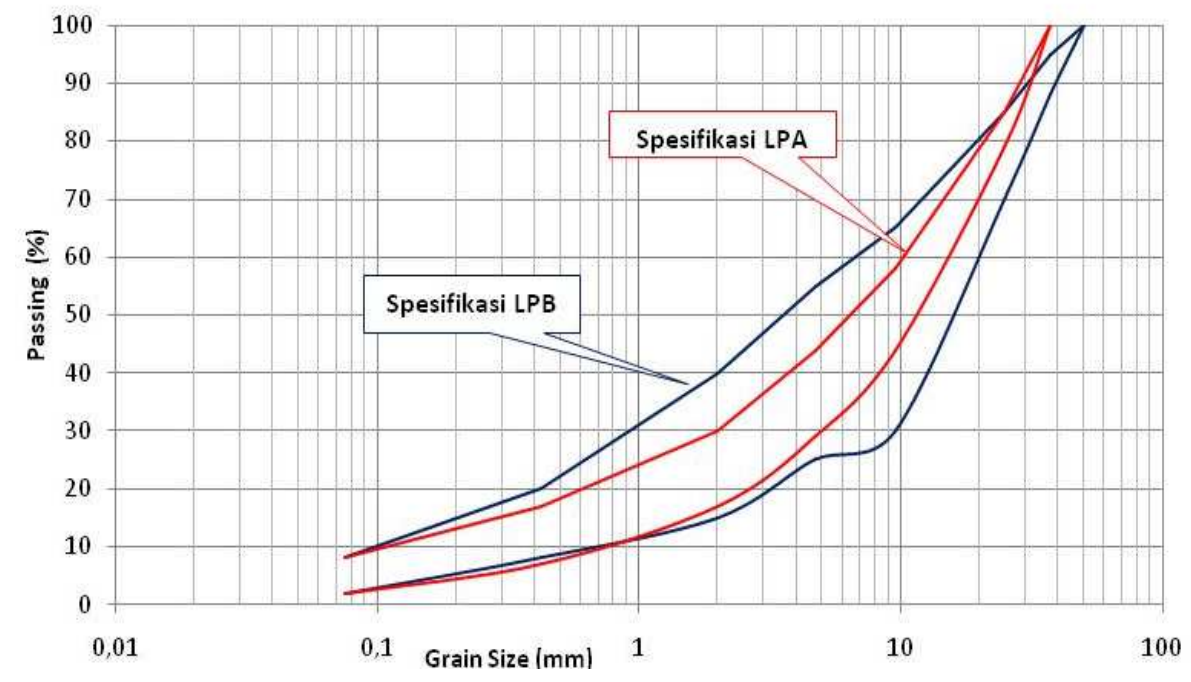

Gambar 1 Batasan minimum dan maksimum distribusi gabungan fraksi agregat kasar dan halus 
Tabel 1 Desain campuran LPA

\begin{tabular}{|c|c|c|c|c|c|c|c|c|c|c|c|c|}
\hline \multirow{3}{*}{$\begin{array}{c}\text { No } \\
\text { Ayakan }\end{array}$} & \multicolumn{9}{|c|}{ Lolos saringan (\%) } & \multirow[b]{3}{*}{8} & \multirow[b]{3}{*}{9} & \multirow[b]{3}{*}{10} \\
\hline & \multicolumn{2}{|c|}{ Spesifikasi } & \multicolumn{7}{|c|}{ Kode sampel LPA- } & & & \\
\hline & maks & Min & 1 & 2 & 3 & 4 & 5 & 6 & 7 & & & \\
\hline $11 / 2$ & 100 & 100 & 100 & 100 & 100 & 100 & 100 & 100 & 100 & 100 & 100 & 100 \\
\hline $1^{\prime \prime}$ & 85 & 79 & 79 & 79 & 79 & 79 & 79 & 79 & 79 & 85 & 79 & 85 \\
\hline $3 / 8^{\prime \prime}$ & 58 & 44 & 47 & 44 & 47 & 47 & 44 & 47 & 47 & 57 & 47 & 44 \\
\hline No.4 & 44 & 29 & 44 & 30 & 44 & 44 & 30 & 44 & 44 & 29 & 29 & 34 \\
\hline No.10 & 29 & 17 & 25 & 28 & 18 & 18 & 28 & 19 & 0 & 0 & 0 & 19 \\
\hline No.40 & 17 & 7 & 8 & 8 & 8 & 7 & 8 & 15 & 0 & 0 & 0 & 16 \\
\hline No.200 & 8 & 2 & 2 & 2 & 2 & 0 & 0 & 0 & 0 & 0 & 0 & 2 \\
\hline
\end{tabular}

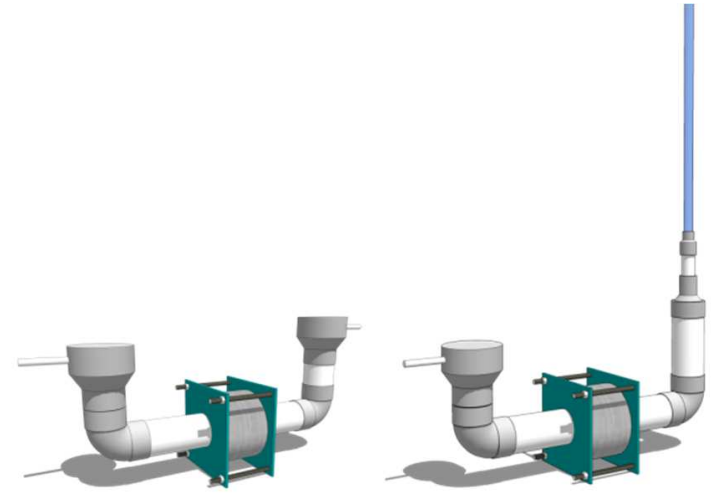

Gambar 2 Alat fabrikasi permeabilitas Horizontal. Kiri: Constant Head. Kanan: Falling head

\section{Hasil Analisa}

\section{Uji Permeabilitas Horizontal}

Nilai koefisien permeabilitas untuk masing-masing tipe pada tiap material dapat dilihat pada Tabel 2 dan Tabel 3.
Tabel 2 Koefisien permeabilitas Horizontal LPA-Gn.

Kayangan.

\begin{tabular}{cc}
\hline Sampel & $\begin{array}{c}\text { Permeabilitas Horizontal } k_{\mathrm{h}} \\
(\mathrm{cm} / \text { det })\end{array}$ \\
\hline LPA-1 Gn. Kayangan & $1,6 \times 10^{-6}$ \\
LPA-2 Gn. Kayangan & $1,5 \times 10^{-5}$ \\
LPA-3 Gn. Kayangan & $2,4 \times 10^{-5}$ \\
LPA-4 Gn. Kayangan & $4,0 \times 10^{-5}$ \\
LPA-5 Gn. Kayangan & $2,4 \times 10^{-5}$ \\
LPA-6 Gn. Kayangan & $8,1 \times 10^{-6}$ \\
LPA-7 Gn. Kayangan & $6,7 \times 10^{-4}$ \\
LPA-8 Gn. Kayangan & $6,8 \times 10^{-4}$ \\
LPA-9 Gn. Kayangan & $6,0 \times 10^{-4}$ \\
LPA-10 Gn. Kayangan & $2,5 \times 10^{-5}$ \\
\hline
\end{tabular}

Tabel 3. Koefisien permeabilitas Horizontal LPA - Katunun

\begin{tabular}{cc}
\hline Sampel & $\begin{array}{c}\text { Permeabilitas Horizontal } k_{\mathrm{h}} \\
(\mathrm{cm} / \mathrm{det})\end{array}$ \\
\hline LPA-6 Katunun & $5,4 \times 10^{-5}$ \\
LPA-7 Katunun & $6,6 \times 10^{-3}$ \\
LPA-8 Katunun & $6,3 \times 10^{-3}$ \\
LPA-8 Katunun DM & $5,5 \times 10^{-2}$ \\
\hline
\end{tabular}

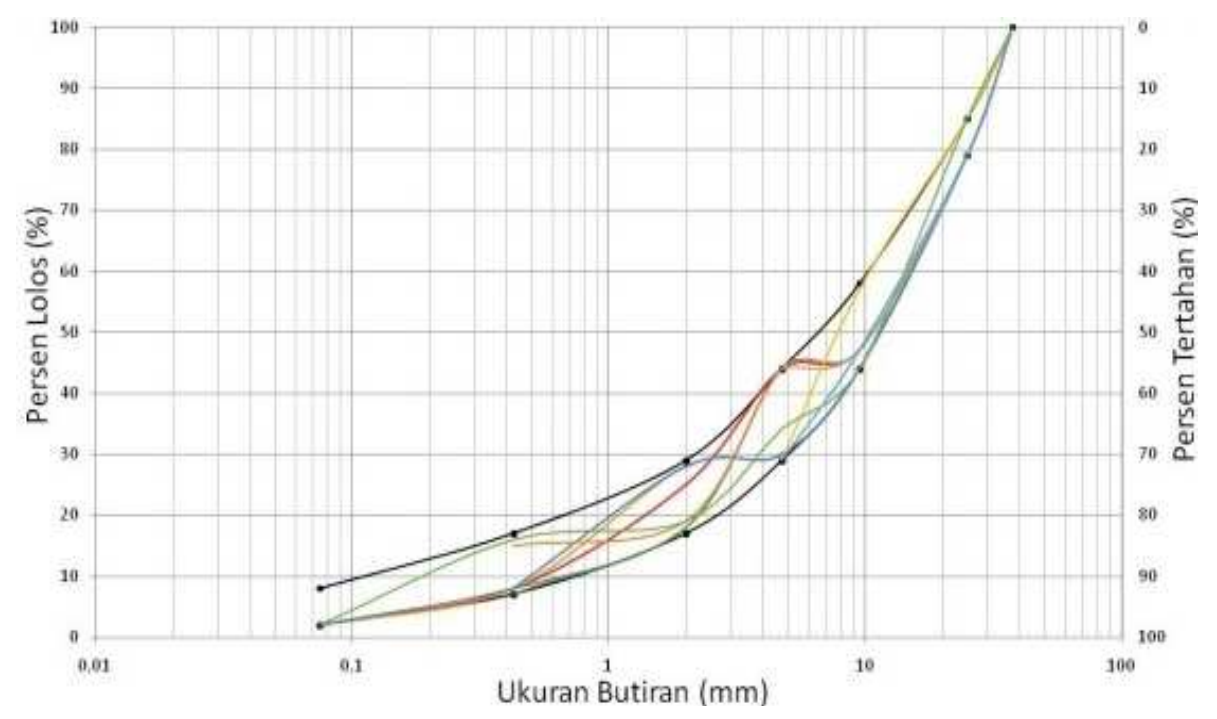

Gambar 3 Kurva gradasi desain LPA 
Pengaruh pemadatan terhadap kurva agregat desain Proses pemadatan atau sering disebut dengan kompaksi yang dilakukan terhadap sampel mengakibatkan pecahnya butiran-butiran agregat. Hal ini dapat dibuktikan dengan cara melakukan uji analisa saringan setelah proses pemadatan selesai dilakukan. Adapun perubahan ukuran butiran dapat dilihat pada perubahan bentuk dan posisi kurva gradasi kedua jenis LPA pada tiap tipe desain gradasi. Kurva gradasi desain ditandai dengan warna merah. Kemudian kurva perubahan gradasi setelah pemadatan untuk sampel LPA - Gn. Kayangan ditandai dengan warna biru. Dan terakhir kurva perubahan gradasi setelah pemadatan untuk sampel LPA - Katunun ditandai dengan warna kuning. Apabila dilihat pada perpindahan posisi kurva, kedua jenis material pada semua tipe campuran ternyata berada di luar dari batas atas spesifikasi yang disediakan. Hal tersebut mengakibatkan gradasi aktual tidak sesuai dengan gradasi desain. Sampel LPA - Gn. Kayangan cenderung melenceng lebih jauh yakni bergeser ke sebelah kiri bila dibandingkan dengan sampel LPA - Katunun. Artinya sampel LPA - Gn. Kayangan mengalami perubahan ukuran butiran menjadi lebih kecil bila dibandingkan dengan LPA Katunun. Hal tersebut menandakan Sampel LPA - Gn. Kayangan lebih aus. Parameter yang cocok menggambarkan tingkat keausan agregat adalah nilai abrasi. Jika dilihat, terdapat pengaruh keausan agregat dengan perubahan ukuran butiran (akibat pemadatan). Gradasi sebelum dan setelah pemadatan dapat dilihat pada Gambar 3. Dilihat hubungan antara gradasi desain dengan gradasi aktual setelah pemadatan. Dilakukan analisis lanjutan menggunakan material dari Katunun. Didapat hubungan yang relatif sama jika dilihat dari rasio perbandingan persen tertahan antara gradasi desain dengan gradasi aktual setelah pemadatan. Apabila nilai rasio tersebut digambarkan ke dalam satu grafik, maka didapatkan bentuk lengkung yang relatif sama seperti terlihat pada Gambar 4. Kemudian dilakukan pendekatan dengan menggunakan grafik polinomial Gambar 5 sehingga didapatkan Persamaan 1.

$$
y=0,00018 x^{2}-0,02674 x+0,95229
$$

Dimana :

$\mathrm{x}=$ Diameter butiran atau bukaan saringan $(\mathrm{mm})$

Persamaan garis tersebut kemudian digunakan untuk merencanakan persen lolos yang telah dikurangi atau digeser mundur terlebih dahulu saat sebelum pengujian. Hal tersebut dilakukan agar diharapkan setelah dilakukan pemadatan bentuk kurva gradasi akan bergeser masuk ke dalam spesifikasi. Persen lolos rencana yang telah dikurangi atau digeser mundur terlebih dahulu tersebut diberi nama desain mundur $(D M)$. Desain mundur persen lolos tersebut kemudian dapat diturunkan menjadi persen tertahan sehingga didapat berat yang diperlukan pada masing-masing saringan saat dilakukan pencampuran. Dipilih satu campuran yang memiliki nilai $k_{\mathrm{h}}$ terbesar pada material Katunun yakni LPA-Katunun 8.

Dari desain mundur tersebut kemudian dilakukan pengujian pemadatan di laboratorium dan uji permeabilitas Horizontal kemudian dilakukan uji analisa saringan sehingga menghasilkan kurva pada Gambar 6. Dari kurva tersebut terlihat realisasi hasil desain mundur mendekati dengan desain yang diharapkan yaitu berada di dalam spesifikasi. Namun pada butiran yang lebih kecil dari nomor saringan 4 masih berada di bawah batas bawah spesifikasi.

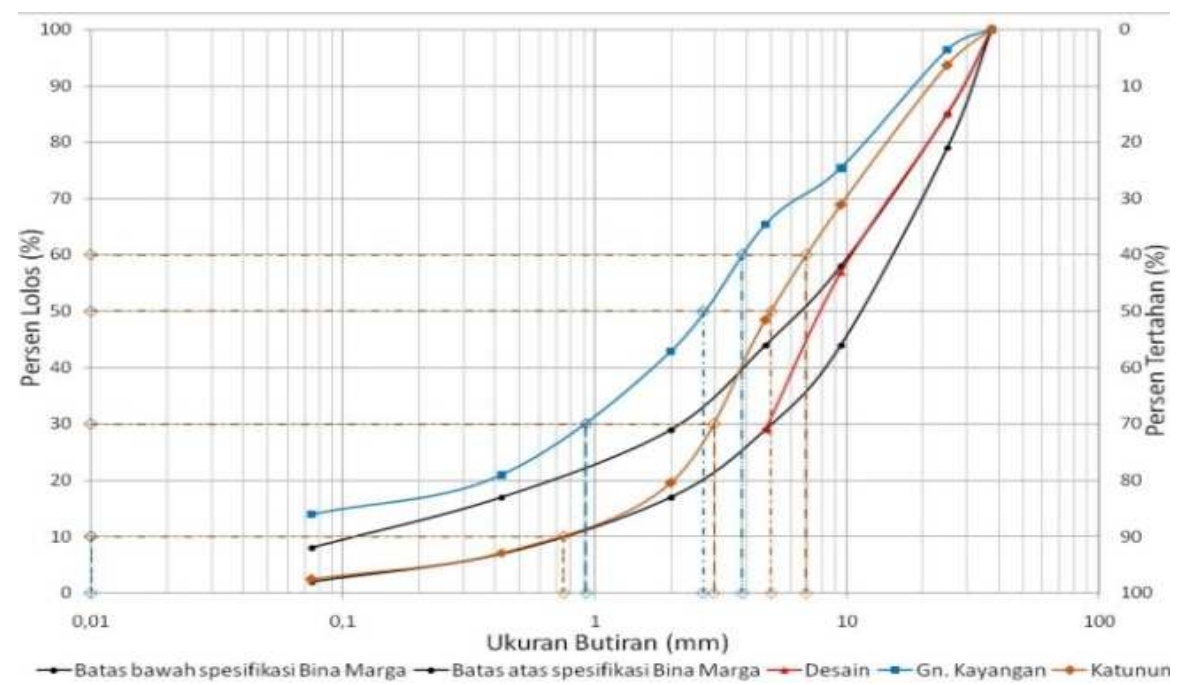

Gambar 4 Gradasi sebelum dan setelah pemadatan 


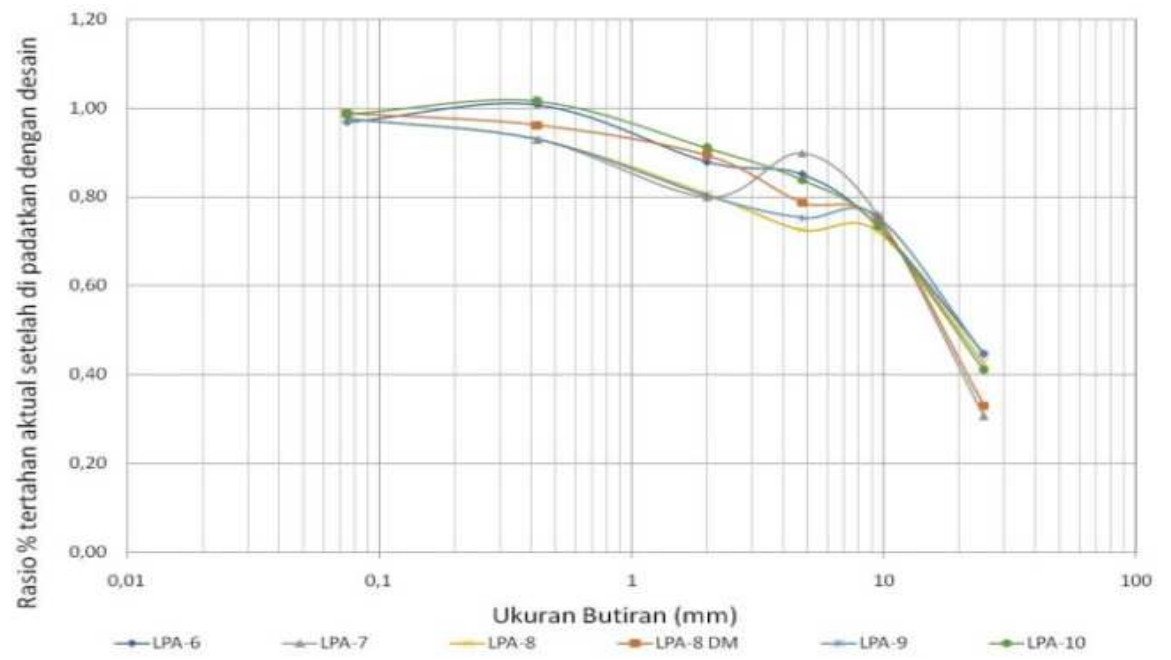

Gambar 5 Hubungan antara diameter butiran dengan rasio persen tertahan

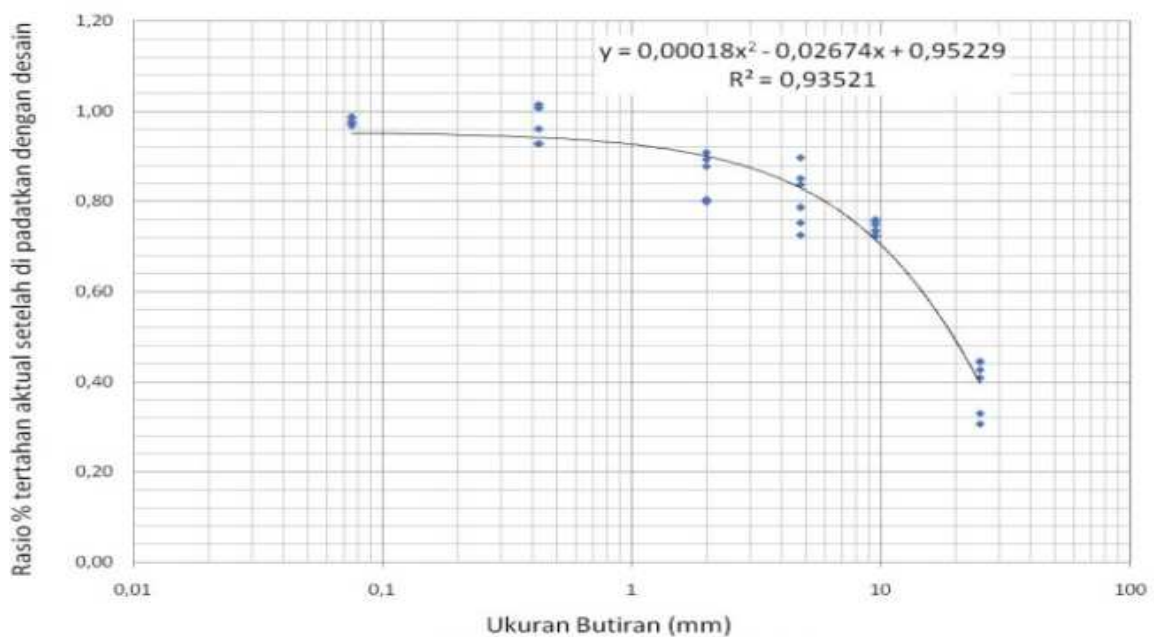

Gambar 6 Persamaan garis polinomial antara diameter butiran dengan rasio \% tertahan

Pengaruh variasi gradasi butiran LPA terhadap kualitas drainase.

Dari berbagai macam variasi campuran sesuai

Gambar 2 2, didapat koefisien permeabilitas yang berbeda-beda. Dari 17 pengujian yang berbeda, didapatkan hasil bahwa perbedaan distribusi butiran mempengaruhi besaran nilai $k_{\mathrm{h}}$. Nilai $k_{\mathrm{h}}$ terbesar dihasilkan oleh tipe gradasi $8 D M$ (desain mundur) yakni $5,52 \times 10^{-2} \mathrm{~cm} /$ det. Kurva gradasi dan grafik uji permeabilitas Horizontal dapat dilihat pada Gambar 7 dan Gambar 8 . Nilai $k_{\mathrm{h}}=5,52 \times 10^{-2} \mathrm{~cm} /$ det apabila dimodelkan ke dalam suatu hitungan untuk mendapatkan lama waktu pengaliran pada penampang melintang suatu jalan kelas I dengan lebar $7 \mathrm{~m}$ seperti Gambar 9.

Badan jalan terdiri dari lapis aus dengan kemiringan $3 \%$, lapis LPA dengan kemiringan permukaan 3\%. Maka didapat air hilang dalam 2,45 hari. Menurut (AASHTO, 1993) drainase termasuk ke dalam kategori drainase dengan kualitas baik menuju sedang karena air hilang dalam waktu kurang dari 1 minggu namun lebih dari 1 hari.

\section{Kesimpulan}

Dari penelitian ini dengan didapat beberapa kesimpulan diantaranya:

1. Terdapat pengaruh pemadatan terhadap ukuran butiran sehingga berdampak pada perubahan bentuk kurva gradasi desain. Pengaruh tersebut berupa pecahnya butiran-butiran yang lebih besar menjadi butiran yang lebih halus sehingga gradasi aktual sudah tidak sesuai lagi dengan gradasi desain.

2. Terdapat perbedaan perilaku pada 2 jenis material yang berbeda walaupun desain gradasinya sama. Sehingga terdapat pengaruh abrasi batu terhadap perubahan bentuk kurva gradasi.

3. Terjadi pertambahan abu batu dan pasir serta kerikil pada LPA setelah dipadatkan sebagai akibat dari proses penumbukan. Sehingga poripori akan terisi oleh butiran halus. 


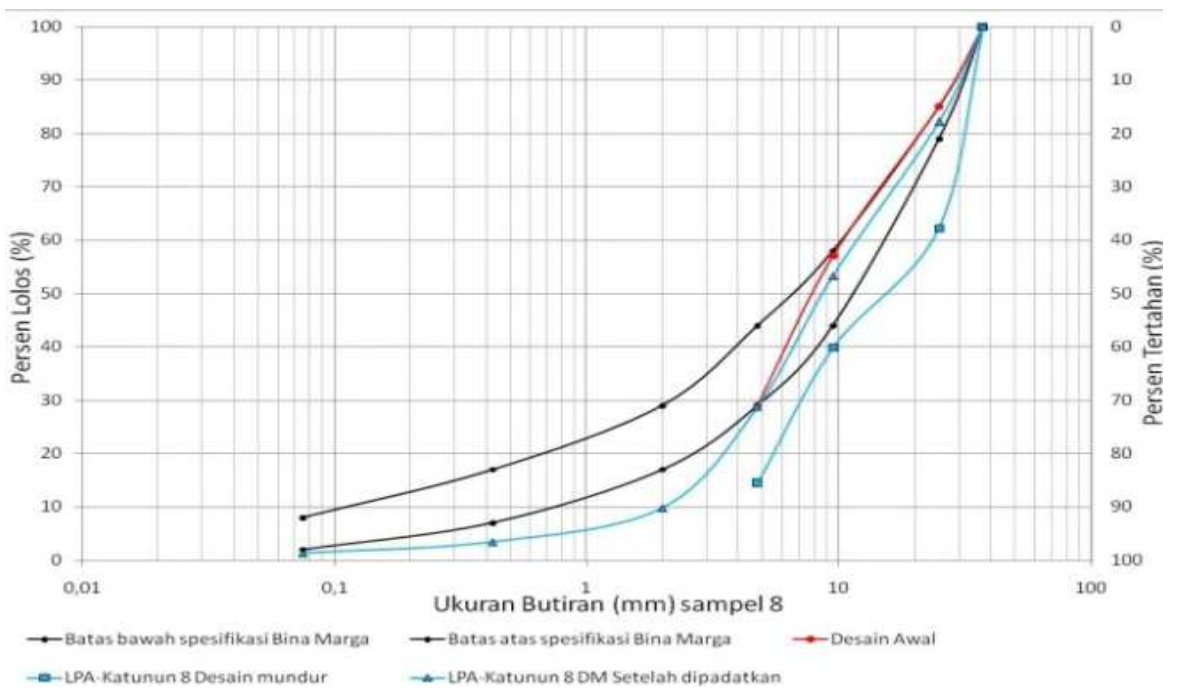

Gambar 7 Gradasi sebelum dan setelah pemadatan kurva yang di desain (DM) di bawah batas bawah spesifikasi

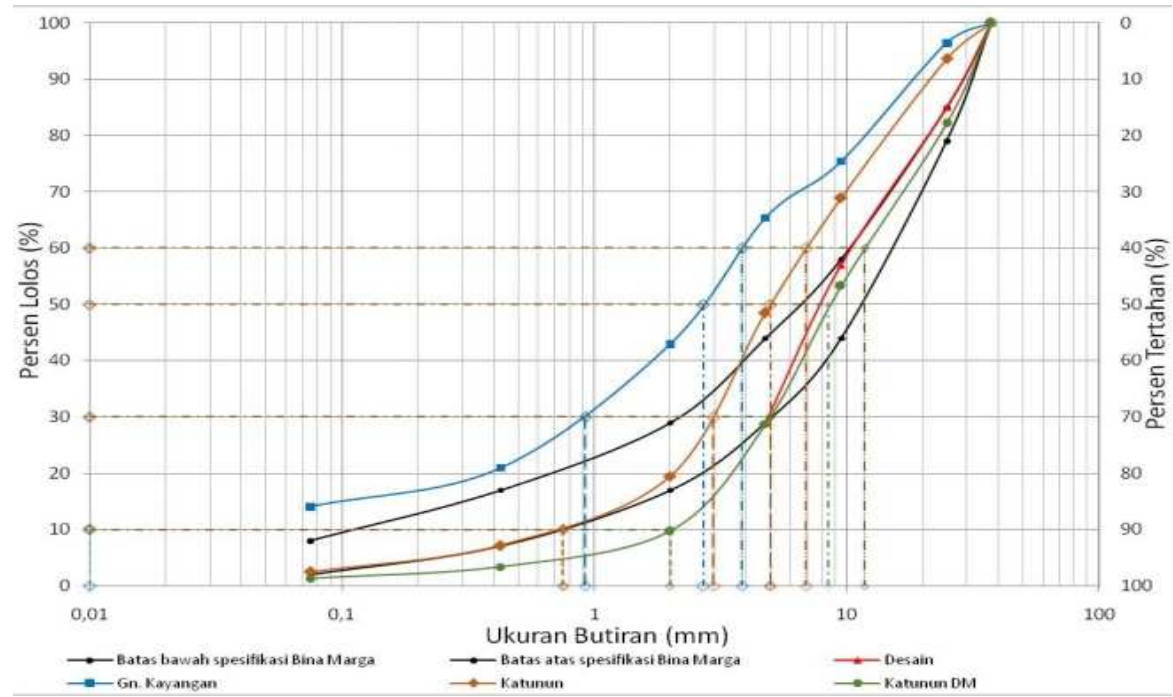

Gambar 8 Gradasi desain dan gradasi setelah pengujian sampel LPA - Katunun 8, LPA 8 Katunun DM dan LPA -8 Gn. Kayangan

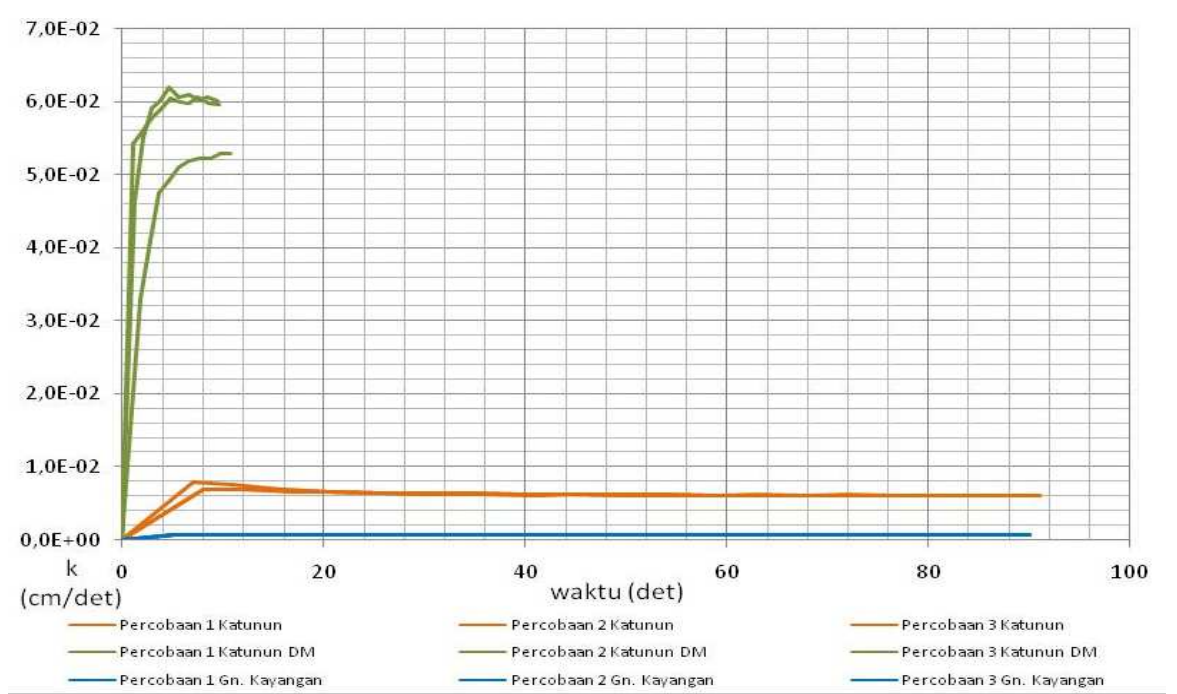

Gambar 9 Grafik hasil uji permeabilitas Horizontal sampel LPA - 8 Katunun, LPA - 8 Katunun DM dan LPA $-8 \mathrm{Gn}$. Kayangan 
4. Gradasi aktual dapat diprediksi dengan menggunakan gradasi yang didesain mundur sesuai pendekatan persamaan $y=0,00018 x^{2}-$ $0,02674 x+0,95229$. Namun persamaan ini hanya teruji pada material dari Katunun dengan nilai abrasi $22,2 \%$.

5. Nilai abrasi mempengaruhi besaran nilai $k_{\mathrm{h}}$. Semakin kecil nilai abrasi maka nilai $k_{\mathrm{h}}$ menjadi relatif lebih besar.

6. Dalam kasus lapangan berupa jalan kelas I lebar $7 \mathrm{~m}$ dan panjang jalur lintasan pengaliran $3,5 \mathrm{~m}$ dengan kemiringan permukaan dasar LPA $3 \%$. Digunakan desain gradasi tipe $8 D M$ material Katunun yang memiliki nilai abrasi $22,20 \%$ dan $k_{\mathrm{h}}$ $=5,52 \times 10^{-2} \mathrm{~cm} /$ det, maka didapat waktu air tidak ada lagi di LPA dalam waktu 2,45 hari. Menurut AASHTO (1993) termasuk ke dalam kategori drainase dengan kualitas baik menuju sedang.

\section{Referensi}

AASHTO (1993) Guide for Design of Pavement Structures. Washington D.C: American Association of State Highway and Transportation Officials.

Aminsyah, M. (2013) Analisa Kehancuran Agregat Akibat Tumbukan Dalam Campuran Aspal. Padang: Jurnal Rekayasa Sipil Volume 9 No. 2

Bina Marga (2010) Spesifikasi Umum Bina Marga 2010 Revisi 3. Kementerian Pekerjaan Umum. Jakarta

Halauddin dan Suhendra. (2011) Pengaruh Penambahan Polimer Emulsi Vinyl Acecate Co Acrylic Pada Tanah Lempung Terhadap Uji Permeabilitas Melalui Constant Head Permeability Test. Semarang: Berkala Fisika Vol. 14 No.2 Hal 55-62

Hendarsin, S.L. (2000). Perencanaan Teknik Jalan Raya. Bandung: Politeknik Negeri Bandung Jurusan Teknik Sipil

Razali, M. R. dan Subagio, B.S. (2012) Perbedaan Gradasi Terhadap Karakteristik Marshall Campuran Beton Aspal Lapis Pengikat (AC-BC). Bengkulu: Jurnal Inersia Volume 4 No. 1

Sukirman, S (2003) Beton Aspal Campuran Panas. Jakarta: Granit

Sukirman, S (2010) Perencanaan Tebal Struktur Perkerasan Lentur. Bandung: Nova. 